\title{
Co-circulation of Influenza A H5, H7, and H9 Viruses and Co-infected Poultry in Live Bird Markets, Cambodia
}

\section{Paul F. Horwood, Srey Viseth Horm, Annika Suttie, Sopheak Thet, Phalla Y, Sareth Rith, San Sorn, Davun Holl, Sothyra Tum, Sowath Ly, Erik A. Karlsson, Arnaud Tarantola, Philippe Dussart}

Longitudinal surveillance of 2 live bird markets in Cambodia revealed year-round, high co-circulation of $\mathrm{H} 5, \mathrm{H} 7$, and $\mathrm{H} 9$ influenza viruses. We detected influenza $\mathrm{A}$ viruses in $51.3 \%$ of ducks and $39.6 \%$ of chickens, and co-infections, mainly by $\mathrm{H} 5$ and $\mathrm{H} 9$ viruses, in $0.8 \%$ of ducks and $4.5 \%$ of chickens.

A large variety of avian influenza viruses (AIVs) circulate in live bird markets (LBMs) in countries where highly pathogenic influenza $\mathrm{A}(\mathrm{H} 5 \mathrm{~N} 1)$ viruses are endemic (1). The low pathogenicity AIVs A(H7N9) and A(H9N2) are also potential threats for global public health, related to the ability of these viruses to cause human infections in people in close contact with infected poultry (2). The segmented genomes of influenza A viruses indicate that co-infections can result in progeny with mixed genomes. Therefore, co-circulation of a large diversity of AIVs is a risk for emergence of novel reassortant viruses affecting animals, humans, or both.

Cambodia is a developing country in Southeast Asia that has a population of $>15$ million, of which $73 \%$ are dependent on agriculture for their livelihood (3). The country is estimated to have a poultry population of $\approx 18$ million chickens and $\approx 8$ million ducks; most are raised in small backyard flocks (4). Poultry are generally transported on trucks and motorbikes into centralized LBMs, where they are slaughtered after being sold to customers (5). These

Author affiliations: Australian Institute of Tropical Health and Medicine, James Cook University, Cairns, Queensland, Australia (P.F. Horwood); Institute Pasteur, Phnom Penh, Cambodia (P.F. Horwood, S.V. Horm, A. Suttie, S. Thet, P. Y, S. Rith, S. Ly,

A. Tarantola, E.A. Karlsson, P. Dussart); Federation University Australia, Churchill, Victoria (A. Suttie); National Animal Health and Production Research Institute, Cambodian Ministry of Agriculture, Forestry and Fisheries, Phnom Penh (S. Sorn, D. Holl, S. Tum)

DOI: https://doi.org/10.3201/eid2402.171360
LBMs have been established as critical for persistence, amplification, and dissemination of AIVs (6).

Surveillance studies in LBMs in Cambodia have revealed some of the highest AIV detection rates in poultry globally $(1,7)$. As of November 2017, a total of 56 human cases (including 37 deaths) and 49 poultry outbreaks of influenza $\mathrm{A}(\mathrm{H} 5 \mathrm{~N} 1)$ have been recorded in Cambodia $(8-10)$. However, little is known about other AIV subtypes at risk for pandemic emergence, mainly $\mathrm{H} 7$ and $\mathrm{H} 9$. We investigated the circulation of potentially highly pathogenic AIV subtypes ( $\mathrm{H} 5, \mathrm{H} 7$, and $\mathrm{H} 9$ ), that have known public health risks in Cambodia LBMs during 2015.

\section{The Study}

We administered a longitudinal survey in 2 LBMs in the highly populated southeast region of Cambodia during February-December (weeks 7-53), 2015. Market 1 is a large LBM in central Phnom Penh that serves as a hub for poultry commerce in the southeast region. Market 2 is a smaller provincial market in Takeo Province. Weekly, we collected pooled oropharyngeal and cloacal swabs from 4 chickens and 4 ducks, randomly selected, in each LBM. We also collected $50-\mathrm{mL}$ samples of carcass wash water (CWW; large buckets of water that are used to wash freshly slaughtered poultry) weekly from each LBM. We transported samples at $4^{\circ} \mathrm{C}$, immediately aliquoted them, and stored them at $-80^{\circ} \mathrm{C}$ until testing.

In the Virology Unit laboratory of Institut Pasteur, Cambodia, we concentrated viruses in the CWW samples as previously described (11). We extracted viral RNA from CWW and swab samples by using the QIAamp Viral RNA Mini Kit (QIAGEN, Valencia, CA, USA), according to the manufacturer's instructions. We then tested extracts for influenza A (M-gene) and subtypes H5 (primer sets H5a and $\mathrm{H} 5 \mathrm{~b}$ ), N1, H7, and $\mathrm{H} 9$ by using quantitative RT-PCR (qRT-PCR) or conventional RT-PCR. The H5, H7, and $\mathrm{H} 9$ gene targets were all tested by using 2 separate assays to reduce the chances of false-negative results caused by the presence of single-nucleotide polymorphisms. Except for 1 of the H7 qRT-PCR and the H9 conventional RT$\mathrm{PCR}$, the assays were sourced from the International Reagent Resource (https://www.internationalreagentresource. org/Home.aspx) (12,13). For the qRT-PCR assays, cycle threshold values $<38$ were considered positive. 
Table 1. Positivity rate for avian influenza viruses in live bird markets, Cambodia, February-December 2015*

\begin{tabular}{|c|c|c|c|c|c|c|c|c|c|}
\hline \multirow[b]{2}{*}{ Type/subtype } & \multicolumn{3}{|c|}{ Market 1, Phnom Penh, no. (\%) } & \multicolumn{3}{|c|}{ Market 2, Takeo, no. (\%) } & \multicolumn{3}{|c|}{ Combined, no. (\%) } \\
\hline & $\begin{array}{l}\text { Chicken, } \mathrm{n} \\
=188\end{array}$ & $\begin{array}{c}\text { Duck, } \mathrm{n}= \\
188\end{array}$ & $\begin{array}{c}\text { CWW, } \mathrm{n}= \\
94\end{array}$ & $\begin{array}{l}\text { Chicken, } \mathrm{n} \\
=188\end{array}$ & $\begin{array}{c}\text { Duck, } \mathrm{n}= \\
188\end{array}$ & $\begin{array}{l}\text { CWW, n } \\
=94\end{array}$ & $\begin{array}{c}\text { Chicken, } \mathrm{n} \\
=376\end{array}$ & $\begin{array}{c}\text { Duck, } \mathrm{n}= \\
376\end{array}$ & $\begin{array}{c}\text { CWW, } \mathrm{n}= \\
188\end{array}$ \\
\hline Influenza A & $89(47.3)$ & $105(55.9)$ & $86(91.5)$ & $60(31.9)$ & $88(46.8)$ & $89(94.7)$ & $149(39.6)$ & $193(51.3)$ & $175(93.1)$ \\
\hline H5 & 41 (21.8) & $53(28.2)$ & $71(75.5)$ & $22(11.7)$ & $24(12.8)$ & $73(77.7)$ & $63(16.8)$ & $77(20.5)$ & $144(76.6)$ \\
\hline N1 & $24(12.8)$ & $21(11.2)$ & $48(51.1)$ & $8(4.3)$ & $9(4.8)$ & $62(66.0)$ & $32(8.5)$ & $30(8.0)$ & $110(58.5)$ \\
\hline $\mathrm{H} 7$ & $1(0.5)$ & $2(1.1)$ & $1(1.1)$ & $1(0.5)$ & $2(1.1)$ & $3(3.2)$ & $2(0.5)$ & $4(1.1)$ & $4(2.1)$ \\
\hline $\mathrm{H} 9$ & $28(14.9)$ & $3(1.6)$ & $54(57.4)$ & $13(6.9)$ & $1(0.5)$ & $22(23.4)$ & $41(10.9)$ & $4(1.1)$ & $76(40.4)$ \\
\hline Co-infections & $15(8.0)$ & $3(1.6)$ & $44(46.8)$ & $2(1.1)$ & 0 & $20(21.2)$ & $17(4.5)$ & $3(0.8)$ & $64(34.0)$ \\
\hline
\end{tabular}

Overall, we collected 940 samples, including 376 chicken swab samples, 376 duck swab samples, and 188 CWW samples. Testing identified AIV RNA year-round from $39.6 \%$ of chickens, $51.3 \%$ of ducks, and $93.1 \%$ of CWW samples (Table 1). We detected H5 in $16.8 \%$ of chickens, $20.5 \%$ of ducks, and $76.6 \%$ of CWW samples; $\mathrm{H} 7$ in $0.5 \%$ of chickens, $1.1 \%$ of ducks, and $2.1 \%$ of $\mathrm{CWW}$ samples; and H9 $10.9 \%$ of chickens, $1.1 \%$ of ducks, and $40.4 \%$ of CWW samples. Market 1 had a higher prevalence than market 2 of most viruses except $\mathrm{H} 7$ viruses, which were detected at similar rates in both markets. The higher rate of virus detection might be a result of the substantially larger size of market 1 , which accommodated more diverse supply chains than did market 2 .

Co-infections were more frequent among chickens $(4.5 \%)$ than ducks $(0.8 \%)$, and high viral loads (determined by qRT-PCR cycle threshold values $<30$ ) of co-infecting viruses were detected in many of the chicken samples
(Table 2). Most co-infections detected were $\mathrm{H} 5$ and $\mathrm{H} 9$ viruses in chickens, particularly from market 1 .

The H5 subtype (37.2\% of birds) was detected much more frequently than $\mathrm{N} 1(16.5 \%)$ by using the subtypespecific qRT-PCR assays. Previous studies have suggested that the sensitivities of M and H5 qRT-PCRs are higher than that for $\mathrm{N} 1$ (1). Isolation and sequence analysis of samples that were $\mathrm{H} 5$ positive and $\mathrm{N} 1$ negative revealed no evidence for circulation of non-N1 H5 strains. Similarly, further investigations were undertaken to confirm that none of the $\mathrm{H} 7$ viruses were H7N9 or HPAI strains (data not shown). The circulation of Eurasian-lineage LPAI H7 viruses in the region has been established through surveillance in South Korea (14).

The peak in AIV and H5N1 circulation occurred during February-April, with a secondary peak during November-December (Figure). Surveillance was not extended into January 2016; however, we assume that the peak

\begin{tabular}{|c|c|c|c|c|c|c|c|c|c|c|c|}
\hline \multirow{2}{*}{$\begin{array}{l}\text { Sample } \\
\text { code }\end{array}$} & \multirow{2}{*}{$\begin{array}{l}\text { Market/ } \\
\text { week }\end{array}$} & \multirow[b]{2}{*}{ Bird } & \multicolumn{7}{|c|}{ Cycle threshold values by quantitative RT-PCR } & \multirow{2}{*}{$\begin{array}{l}\text { H9 RT- } \\
\text { PCRI }\end{array}$} & \multirow{2}{*}{$\begin{array}{c}\text { Co- } \\
\text { infections }\end{array}$} \\
\hline & & & Influenza A†‡ & H5a† & $\mathrm{H} 5 \mathrm{~b} \dagger$ & $\mathrm{N} 1 \dagger$ & $\mathrm{H} 7 \S$ & $\mathrm{H} 7 \dagger$ & $\mathrm{H} 9 \dagger$ & & \\
\hline Z-47 & M1/W9 & $\mathrm{C}$ & 18.72 & 18.96 & ND & 23.57 & - & - & 20.37 & + & $\mathrm{H} 5 \mathrm{~N} 1 / \mathrm{H} 9$ \\
\hline Z-68 & M1/W10 & $\mathrm{C}$ & 19.38 & 26.94 & ND & 25.41 & - & - & 30.82 & + & $\mathrm{H} 5 \mathrm{~N} 1 / \mathrm{H} 9$ \\
\hline Z-104 & M1/W12 & D & 24.13 & 32.73 & 30.74 & 32.90 & - & - & 23.39 & + & $\mathrm{H} 5 \mathrm{~N} 1 / \mathrm{H} 9$ \\
\hline Z-138 & M2/W13 & C & 26.02 & 28.04 & 25.84 & 25.37 & - & - & 29.02 & + & $\mathrm{H} 5 \mathrm{~N} 1 / \mathrm{H} 9$ \\
\hline Z-150 & M1/W14 & C & 34.25 & 27.01 & 39.76 & - & - & - & 34.47 & + & H5/H9 \\
\hline Z-167 & M1/W15 & C & 30.81 & 38.60 & 36.36 & - & - & - & 30.84 & + & H5/H9 \\
\hline Z-169 & M1/W15 & C & 27.83 & 37.93 & 35.08 & - & - & - & 27.58 & + & H5/H9 \\
\hline Z-170 & M1/W15 & C & 22.79 & 33.52 & 32.44 & 34.79 & - & - & 25.65 & + & $\mathrm{H} 5 \mathrm{~N} 1 / \mathrm{H} 9$ \\
\hline Z-227 & M1/W18 & C & 28.90 & 35.77 & 29.81 & 30.17 & - & - & 30.60 & + & $\mathrm{H} 5 \mathrm{~N} 1 / \mathrm{H} 9$ \\
\hline Z-228 & M1/W18 & C & 23.93 & 29.54 & 23.63 & 24.60 & - & - & 29.84 & + & $\mathrm{H} 5 \mathrm{~N} 1 / \mathrm{H} 9$ \\
\hline Z-230\# & M1/W18 & C & 25.61 & - & 39.71 & 38.54 & - & - & 22.65 & + & $\mathrm{H} 5 \mathrm{~N} 1 / \mathrm{H} 9$ \\
\hline Z-267 & M1/W20 & C & 22.70 & 28.69 & 26.80 & 30.18 & - & - & 27.66 & + & $\mathrm{H} 5 \mathrm{~N} 1 / \mathrm{H} 9$ \\
\hline Z-269\# & M1/W20 & C & 21.04 & - & - & - & - & - & 27.00 & + & $\mathrm{H} 5 \mathrm{~N} 1 / \mathrm{H} 9$ \\
\hline Z-430 & M1/W28 & C & 23.79 & - & - & - & - & 24.78 & 24.98 & + & H7/H9 \\
\hline Z-466 & M1/W30 & D & 32.56 & 40.93 & - & - & - & 34.72 & 36.00 & + & $\mathrm{H} 7 / \mathrm{H} 9$ \\
\hline Z-568\# & M1/W35 & C & 32.40 & - & 41.34 & - & - & - & 37.39 & + & $\mathrm{H} 5 \mathrm{~N} 1 / \mathrm{H} 9$ \\
\hline Z-748\# & M1/W44 & C & 21.05 & - & 35.44 & 37.75 & - & - & 27.17 & + & $\mathrm{H} 5 \mathrm{~N} 1 / \mathrm{H} 9$ \\
\hline Z-824 & M1/W48 & D & 19.40 & 17.20 & 23.82 & 25.38 & - & - & 31.79 & - & $\mathrm{H} 5 \mathrm{~N} 1 / \mathrm{H} 9$ \\
\hline Z-858\# & M2/W49 & C & 18.41 & 40.23 & - & 24.02 & - & - & 27.67 & + & $\mathrm{H} 5 \mathrm{~N} 1 / \mathrm{H} 9$ \\
\hline Z-909\# & M1/W52 & C & 24.14 & 38.03 & 39.37 & - & - & - & 29.88 & + & H5/H9 \\
\hline
\end{tabular}

${ }^{*} \mathrm{C}$, chicken; D, duck; RT-PCR, reverse transcription PCR; +, positive; -, negative.

†US Centers for Disease Control and Prevention assays, available at the International Reagent Resource (https://www.internationalreagentresource.org/Home.aspx).

$\ddagger$ All samples with an M gene quantitative RT-PCR cycle threshold value $<38$ were inoculated into embryonated chicken eggs to confirm avian influenza infection.

§Van Borm et al. (13).

TWorld Health Organization (12).

\#Equivocal $\mathrm{H} 5$ or $\mathrm{N} 1$ results (defined by cycle threshold value $>38$ ) were subsequently confirmed by isolation of influenza $\mathrm{A}(\mathrm{H} 5 \mathrm{~N} 1$ ) in embryonated chicken eggs (data not shown). 


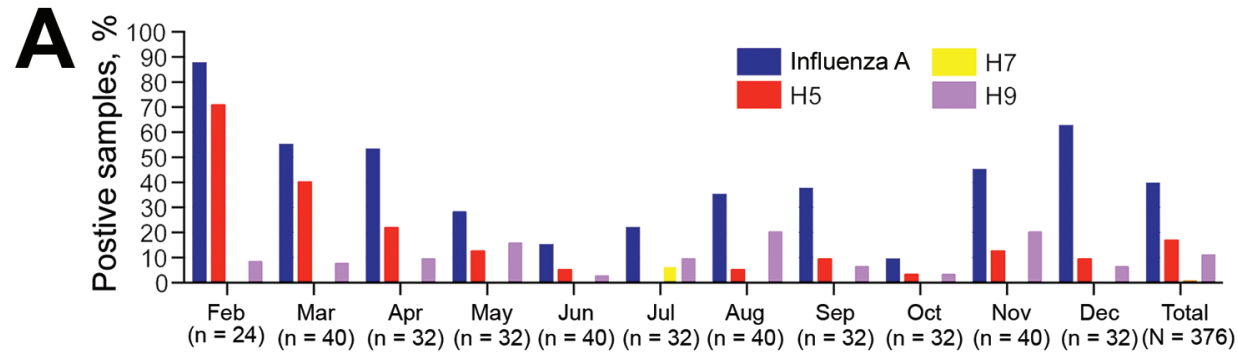

B

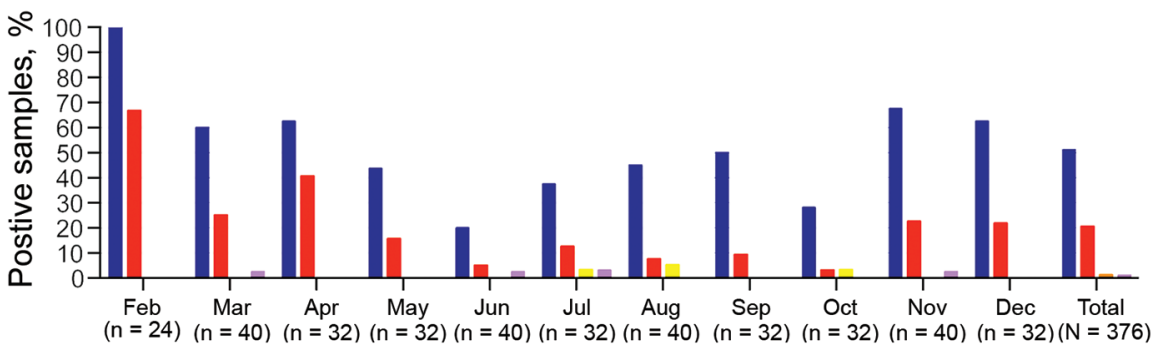

Figure. Seasonality of avian influenza subtype circulation in live bird markets in Cambodia during 2015, as detected by quantitative reverse transcription PCR. A) Oropharyngeal and cloacal swabs from chickens; B) oropharyngeal and cloacal swabs from ducks; C) carcass wash water samples from pooled chickens and ducks after euthanization.
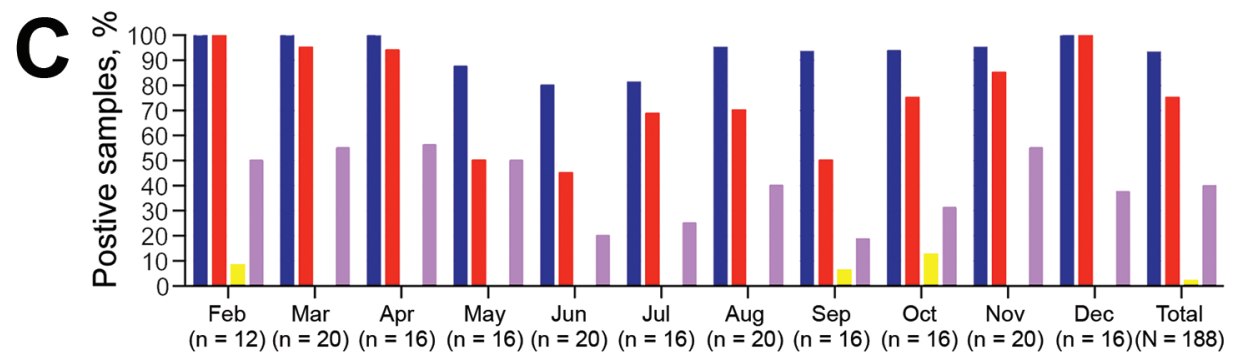

period extends from November through April, coinciding with the dry season in Cambodia. Similar seasonality of AIV circulation was observed in a longitudinal LBM study in 2013, in which February was also the month with the highest prevalence of AIV-infected poultry (1). Knowledge of this peak period of circulation is needed so that animal and human health authorities can target interventions to reduce AIV spread and human exposure. We detected H9 circulation in chickens year-round, with no discernible seasonality. H7 seasonality could not be determined because of the small number of viruses detected.

\section{Conclusions}

Throughout the study, we detected high levels of AIVs in 2 LBMs in southeastern Cambodia. In 2013, our research team conducted a similar longitudinal AIV surveillance study that included the same 2 LBMs (referred to as M1, Phnom Penh, and M4, Takeo, in the 2013 study [1]). In that study, we detected AIVs in $32 \%$ of ducks, $18 \%$ of chickens, and $75 \%$ of CWW samples. This new study found a substantial increase in circulation of AIVs: $51 \%$ of ducks, $40 \%$ of chickens, and $93 \%$ of CWW samples. However, no corresponding increase in cases of H5N1 infection among humans was detected in Cambodia during 2015, possibly related to the replacement of the $\mathrm{H} 5 \mathrm{~N} 1$ clade 1.1.2 reassortant virus with an H5N1 clade 2.3.2.1c virus in early 2014.
The detection of co-infections in $4.5 \%$ of chickens during this study was cause for concern. Reassortment between $\mathrm{H} 5 \mathrm{~N} 1$ and other AIVs could produce novel viruses that have potential to cause epizootics or pandemic emergence. Reassortment with the internal genes of H9N2 viruses has been linked to the emergence of numerous AIVs that raise public health concern, such as $\mathrm{H} 5 \mathrm{~N} 1, \mathrm{H} 7 \mathrm{~N} 9$, and H10N8 (15). In this study, only H5, H7, and H9 subtypes were screened, because strains of these viruses (particularly $\mathrm{H} 5 \mathrm{~N} 1, \mathrm{H} 7 \mathrm{~N} 9$, and $\mathrm{H} 9 \mathrm{~N} 2$ ) are of leading global health concern. We would expect an even higher detection rate of co-infections if all AIV subtypes were tested.

In summary, we have documented a substantial increase in the prevalence of AIVs in Cambodian LBMs from 2011 (7) to 2013 (1) to 2015. We also have established that co-infections between AIVs commonly occur in the LBM environment and there is potential for emergence of novel viruses through reassortment. Interventions should be considered to decrease the prevalence of AIVs in LBMs to reduce the risk for emergence of novel viruses.

\section{Acknowledgments}

We thank the vendors from the participating live bird markets for their cooperation with our study team. We also thank the technical team from the Virology Unit at the Institute Pasteur in Cambodia and the field teams from the National Animal Health 
and Production Research Institute (Cambodian Ministry of Agriculture, Forestry and Fisheries) and the Epidemiology and Public Health Unit at the Institute Pasteur in Cambodia.

This study was funded by the US Department of Health and Human Services, Office of the Assistant Secretary for Preparedness and Response (grant No. IDSEP 140020-01-00; http://www.asideproject.org/).

\section{About the Author}

Dr. Horwood conducted this study as the deputy head of the Virology Unit at the Institut Pasteur in Cambodia. He is now a senior research fellow at the Australian Institute of Tropical Health and Medicine, James Cook University, Cairns, Queensland, Australia. His research interests include molecular characterization and epidemiology of emerging tropical infectious diseases.

\section{References}

1. Horm SV, Tarantola A, Rith S, Ly S, Gambaretti J, Duong V, et al. Intense circulation of $\mathrm{A} / \mathrm{H} 5 \mathrm{~N} 1$ and other avian influenza viruses in Cambodian live-bird markets with serological evidence of sub-clinical human infections. Emerg Microbes Infect. 2016;5:e70. http://dx.doi.org/10.1038/emi.2016.69

2. Pu J, Wang S, Yin Y, Zhang G, Carter RA, Wang J, et al. Evolution of the H9N2 influenza genotype that facilitated the genesis of the novel H7N9 virus. Proc Natl Acad Sci U S A. 2015;112:548-53. http://dx.doi.org/10.1073/pnas.1422456112

3. Goutard FL, Binot A, Duboz R, Rasamoelina-Andriamanivo H, Pedrono M, Holl D, et al. How to reach the poor? Surveillance in low-income countries, lessons from experiences in Cambodia and Madagascar. Prev Vet Med. 2015;120:12-26. http://dx.doi.org/10.1016/j.prevetmed.2015.02.014

4. Ministry of Agriculture Forestry and Fisheries (MAFF). 2014: Overview of the livestock industry in Cambodia [cited 2017 Jun 8]. http://www.dahp-maff.org/blog/overview-of-the-livestockindustry/

5. Van Kerkhove MD, Vong S, Guitian J, Holl D, Mangtani P, San S, et al. Poultry movement networks in Cambodia: implications for surveillance and control of highly pathogenic avian influenza (HPAI/H5N1). Vaccine. 2009;27:6345-52. http://dx.doi.org/10.1016/j.vaccine.2009.05.004
6. Guan Y, Smith GJ. The emergence and diversification of panzootic H5N1 influenza viruses. Virus Res. 2013;178:35-43. http://dx.doi.org/10.1016/j.virusres.2013.05.012

7. Horm SV, Sorn S, Allal L, Buchy P. Influenza A(H5N1) virus surveillance at live poultry markets, Cambodia, 2011. Emerg Infect Dis. 2013;19:305-8. http://dx.doi.org/10.3201/eid1902.121201

8. Buchy P, Fourment M, Mardy S, Sorn S, Holl D, Ly S, et al. Molecular epidemiology of clade 1 influenza A viruses (H5N1), southern Indochina peninsula, 2004-2007. Emerg Infect Dis. 2009;15:1641-4. http://dx.doi.org/10.3201/eid1510.090115

9. Rith S, Davis CT, Duong V, Sar B, Horm SV, Chin S, et al. Identification of molecular markers associated with alteration of receptor-binding specificity in a novel genotype of highly pathogenic avian influenza $\mathrm{A}(\mathrm{H} 5 \mathrm{~N} 1)$ viruses detected in Cambodia in 2013. J Virol. 2014;88:13897-909. http://dx.doi.org/10.1128/ JVI.01887-14

10. ProMED-mail. Avian influenza (37): Cambodia (SR) poultry, HPAI H5N1, OIE [cited 2017 Jun 8]. https://www.promedmail.org, archive no. 20170131.4806507.

11. Horm SV, Gutiérrez RA, Sorn S, Buchy P. Environment: a potential source of animal and human infection with influenza A (H5N1) virus. Influenza Other Respir Viruses. 2012;6:442-8. http://dx.doi.org/10.1111/j.1750-2659.2012.00338.x

12. World Health Organization. Recommended laboratory tests to identify avian influenza A virus in specimens from humans. June 2005 [cited 2017 Jun 8]. http://www.cdc.gov.tw/professional/ downloadfile.aspx?fid=A3FADEF4E0765B48

13. Van Borm S, Suarez DL, Boschmans M, Ozhelvaci O, Marché S, van den Berg TP. Rapid detection of Eurasian and American H7 subtype influenza A viruses using a single TaqManMGB real-time RT-PCR. Avian Dis. 2010;54(Suppl):632-8. http://dx.doi.org/10.1637/8734-032509-ResNote.1

14. Kang HM, Park HY, Lee KJ, Choi JG, Lee EK, Song BM, et al. Characterization of $\mathrm{H} 7$ influenza A virus in wild and domestic birds in Korea. PLoS One. 2014;9:e91887. http://dx.doi.org/10.1371/ journal.pone.0091887

15. Gu M, Chen H, Li Q, Huang J, Zhao M, Gu X, et al. Enzootic genotype $\mathrm{S}$ of $\mathrm{H} 9 \mathrm{~N} 2$ avian influenza viruses donates internal genes to emerging zoonotic influenza viruses in China. Vet Microbiol. 2014;174:309-15. http://dx.doi.org/10.1016/j.vetmic.2014.09.029

Address for correspondence: Paul F. Horwood, Australian Institute of Tropical Health and Medicine, James Cook University, PO Box 6811, Cairns, QLD 4870, Australia; email: paul.horwood@jcu.edu.au

\title{
PubMed Central
}

\section{PublMled}

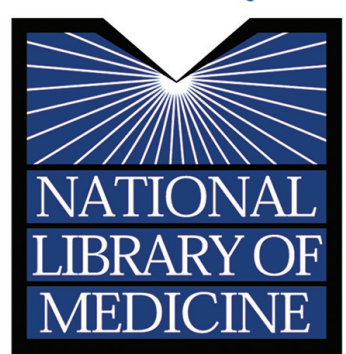

\section{Find Emerging Infectious Diseases content in the digital archives of the National Library of Medicine}

\author{
www.pubmedcentral.nih.gov
}

